We wish to take this opportunity for correcting a few minor misprints in our published tables of structures (which contain some 200 components). These appeared only on printing and have no effect on the reported analysis. In $\lambda 4513$ read 180 for 150 ; in $\lambda 4391$ read $\widetilde{90}$ for $\widetilde{182}$; in $\lambda 8334$ (Fig. 3) read 163,195 for 153,185 (calc.), and 162,195 for 152 , 185 (obs.), in $\lambda 4592 \mathrm{read} \widetilde{165}$ for $\widetilde{65}$.

S. Tolansky.

S. A. Trivedi.

Physics Department,

University,

Manchester.

Oct. 28 .

${ }^{2}$ Tolansky, S., and Trivedi, S. A., Proc. Roy. Soc., A, 175, 366 (1940).

\section{Ability of Respiratory-Stimulating Factors to Overcome Toxic Action of Germicides on Moulds}

IT is well known that germicides depress the respiration of both the micro-organisms and the tissues with which they come in contact. It has been shown that the depressant actions of a germicide on the respiration of the micro-organism and of the host tissue are directly correlated with the toxicities of the germicide for the organism and the host, and a comparison of these respiratory effects by manometric methods has been proposed for the evaluation of germicides ${ }^{1}$.

In our laboratories it has been found ${ }^{2}$ that the depressant action of germicides on the respiration of tissues can be overcome in vitro by the addition of various fractions from yeast which have been found previously to increase the respiration of yeast and tissues $^{3}$. It has also been found that for certain of these fractions the ability to stimulate the respiration of yeast parallels the ability to stimulate yeast proliferation 4 , although this is not always the case. In view of these two lines of work it became of interest to determine the effects of germicides and of certain of these respiratory-stimulating fractions $\left(R S F^{\prime}\right)$ on the growth of moulds.

In typical experiments 28 Petri dishes were prepared containing Czapek's medium with different concentrations of germicide. These dishes were divided into four sets of seven each. The dilutions of germicide in each set were $I: 1000 ; 1: 10,000$, $1: 20,000,1: 50,000,1: 100,000$ and no germicide, two sets containing phenyl mercuric nitrate ${ }^{5}$ and two containing $n$-butyl-parahydroxybenzoate ${ }^{6}$. The medium in one set of each group contained one per cent of the RSF. Two sets were seeded with Aspergillus niger and two with Penicillium glabrum by placing one loopful of a sterile water suspension of the mould in the centre of the Petri dish. The fungi were grown at room temperature in the dark and were examined at intervals for a period of 14 days. Phenylmercuric nitrate alone was effective in inhibiting completely the growth of $A$. niger in a concentration of $1: 100,000$ and of $P$. glabrum at $1: 20,000$. Addition of one per cent of crude $R S F$ (corresponding to Fraction $A^{3}$ ) not only increased growth in the lower germicide concentrations where some growth took place normally, but caused growth equal to that of the control with the usually completely inhibitory germicide concentrations of $1: 100,000$ and $1: 50,000$ for $A$. niger and $1: 20,000$ for $P$. glabrum. Similar although quantitatively different results were obtained with Butaben. All experiments were repeated using Sabouraud's medium with similar results.

Experiments have further indicated that the crude yeast $R S F$ also contains factors inhibitory to mould growth, that both the inhibitory and stimulatory factors are soluble in 85 per cent acetone, but that the inhibitory factor can apparently be removed by adsorption on charcoal. The acetone-soluble fraction is the most active of the fractions in increasing the respiration ${ }^{3}$ and growth ${ }^{4}$ of yeast and is inactive on the respiration of rat skin. ${ }^{3}$ On the other hand, the acetone-insoluble fraction increases the respiration of skin but is not particularly active in stimulating growth and respiration of yeast or growth of moulds. It may thus be possible to use these active fractions in overcoming some of the toxic effects of germicides on the host without greatly impairing germicidal efficiency, and this possibility is being studied.

These facts are consistent with an interrelation between proliferation and respiration, although in many cases a more direct correlation has been found between glycolysis and growth ${ }^{7}$. This interrelationship is under investigation, as is the purification of the factors responsible for the observed effects.

Details of these experiments will be published later.

ELTON S. CoOK.

Cornelius W. Kreke.

Research Laboratories,

Institutum Divi Thomae, Cincinnati, Ohio.

Oct. 2 .

${ }^{1}$ Bronfenbrenner, J., Hershey, A. D., and Doubly, J., J. Bact., 37, 583 (1939) ; Ely, J. O., ibid., 38, 391 (1939) ; ef. also Miller, B. F.' and Baker, Z., Science, 91, 624 (1940).

${ }^{2}$ Cook, E. S., and Kreke, C. W., unpublished.

${ }^{3}$ Cook, E. S., Kreke, C. W., and Nutini, I. G., Studies Inst. Divi Thomce, 2, 23 (1938)

4 Cook, E. S., Hart, M. J., and Stimson, M. M., in publication.

5 Weed, L. A., and Ecker, E. E., J. Infect. Dis., 49, 440 (1931) ; 52, 354 (1933).

${ }^{6}$ Butaben, Merck. We wish to thank Dr. R. T. Major of Merck and Co., Ine., for a gift of this material:

? Trowell, O. A and Willmer, E. N., J. Exptl. Biol., 16, 60 (1939) Pomerat, C. M., and Willmer, E. N., ibid., 16, 232 (1939).

\section{Siegesbeckia orientalis in Britain}

$\mathrm{IT}_{\mathrm{T}}$ is interesting to note that almost simultaneously with the publication of the note in NATURE of October 12 of the twelve-year establishment of a colony of the alien composite Siegesbeckia orientalis at Freshfield Station, Lancashire (botanical vice-county 59), I have been able to add to my herbarium a specimen from a new station at Rufford, twelve miles inland westwards, and it is of further interest that some of the flower-heads have six bracts. It appears that the Rufford colony has been growing for some years in a sandy wild garden but was only recently identified in our work on the local flora for the Rufford Village Museum exhibit. It was locally believed that the plants might have been introduced with poultry food for they flourish abundantly and spread rapidly, especially after a bonfire. There is, nevertheless, the possibility of birds or hares transporting seeds adhering to sticky bracts from the Freshfield site.

Merseyside Naturalists' Association,

ERIC Hardy.

Oct. 19. 